\title{
Digital storytelling: una nueva estrategia para narrar historias y adquirir competencias por parte de los futuros maestros
}

\section{Digital storytelling: a new strategy for storytelling and acquired competencies by future teachers}

\author{
Lourdes VILLALUSTRE MARTÍNEZ y Mª Esther DEL MORAL PÉREZ \\ Universidad de Oviedo
}

Recibido: Enero 2013

Aceptado: Febrero 2013

\section{Resumen}

El digital storytelling o relato digital se ha convertido en un nuevo arte narrativo presente en el ámbito cultural y educativo, capaz de integrar recursos multiformato para presentar y conceptualizar la información, a partir de un lenguaje hipermedial. Dadas sus potencialidades, durante el curso académico 2010/11 en la asignatura de Tecnologías de la Información y Comunicación aplicadas a la Educación Primaria, se llevó a cabo una experiencia formativa basada en el diseño de digital storytelling por parte de los estudiantes universitarios. En ella, los futuros maestros debían elaborar un cuento, a través de la técnica de animación stop-motion, para su explotación didáctica en el aula de primaria, con el fin de transmitir valores como la amistad, la solidaridad, el respeto, etc. Tras su realización se pudo constatar el grado de adquisición de competencias adquiridas por los dicentes, que va desde el bajo, pasando por el medio para llegar al alto. Dichas competencias se clasificaron en cuatro dimensiones: competencias digitales, narrativas, creativas y didácticas. Entre los resultados obtenidos, cabe destacar que más de la mitad de los futuros maestros mostraron poseer un alto nivel de competencias y algo más del $38 \%$ un nivel medio. De igual modo, un análisis más especifico reveló que un alto porcentaje $(67,3 \%$ y $57,2 \%)$ de futuros maestros mostró haber logrado un alto nivel de competencias creativas y digitales. Mientras que algo menos de la mitad (41,6\%) de los discentes obtuvo un nivel alto de competencias narrativas.

Palabras clave: narración de historias, medios audiovisuales, competencia, estrategia didáctica

\begin{abstract}
The digital storytelling has become a new narrative art present in the cultural and educational resources capable of integrating multiple formats present and conceptualize information from hypermedia language. Given its potential, during the academic year 2010/11 in the subject of Information Technology and Communication applied to primary education, was conducted based on a formative experience designing digital storytelling by college students. In the


activity, students should develop a story through the art of stop-motion animation, for exploitation didactic classroom elementary, to transmit the values of friendship, solidarity, respect, etc. After its completion it was found the degree of acquisition of competences acquired by students, ranging from low, to medium to reach the top. The competences were classified into four dimensions: digital competences, narrative, creative and educational. Among the results, it is noteworthy that more than half of future teachers have demonstrated a high level of competences and more than $38 \%$ a medium level. Similarly, a more specific analysis showed that a high percentage $(67.3 \%$ and $57.2 \%)$ of students showed to have achieved a high level of creative and digital competences. While just under half (41.6\%) of the students obtained a high level of narrative skills.

Keywords: storytelling, media, competence, teaching strategy

La generalización paulatina del uso de herramientas digitales ha supuesto un cambio importante en el modo en el que los usuarios acceden a la información e incluso contribuyen a su elaboración y presentación. La Web 2.0 está permitiendo generar espacios colaborativos que hacen posible que los usuarios elaboren píldoras de información, relatos digitales y todo tipo de historias que pueden compartir entre ellos a través de las distintas redes sociales, utilizando fórmulas narrativas e instrumentos tecnológicos sencillos capaces de integrar recursos multiformato (imágenes, vídeos, audio, locuciones, etc.), dotándolos de gran impacto sensorial, valor expresivo y comunicativo.

Nos hallamos en un punto de inflexión en el que los receptores se convierten también en emisores y el flujo de la información ya no es unidireccional. Del mismo modo, los usuarios que antes eran meros consumidores de productos audiovisuales creados por otros, ahora adoptan papeles más activos, son diseñadores de sus propias creaciones y participan en todo el proceso creativo, formando parte de la historia y controlando aspectos estéticos e iconográficos (Meadows, 2003). Lógicamente, ello implica una mayor capacitación, dominio tanto de los medios digitales y el lenguaje audiovisual, como de las herramientas o aplicaciones informáticas que permitan elaborar mensajes incisivos o relatos atractivos de forma ágil en formato digital.

Así pues, asistimos a una nueva era en la que la forma de narrar historias no se adscribe a la convencional estructura lineal, y donde la integración de recursos diversos puede enriquecerlas, dando origen a los relatos digitales o digital storytelling, con los cuales es posible organizar una gran variedad de recursos multimedia a partir de la narrativa tradicional (Lambert, 2007). La naturaleza abierta y flexible de los digital storytelling propicia la interacción comunicativa, el desarrollo de la creatividad y la imaginación, utilizando la lógica de la imagen como estrategia comunicativa (Lundby, 2008).

Digital Storytelling o relato digital es una novedosa técnica narrativa que facilita la presentación de ideas, la comunicación o transmisión de conocimientos, mediante un peculiar modo de organizar y presentar la información de carácter multiformato, apoyado en el uso de soportes tecnológicos y digitales de diversa índole, entre ellas las herramientas Web 2.0. Su proceso de construcción y elaboración de historias brinda la 
oportunidad de generar atractivos escenarios para el aprendizaje, en los que cada cual puede adoptar el rol de productor de contenidos audiovisuales (Hull \& Katz, 2006). Ello implica la puesta en juego de la capacidad narrativa y creativa de los autores, tomando como punto de partida el diseño de un guión inicial o storyboard, así como el desarrollo de las habilidades y competencias específicas necesarias para interactuar en un entorno tecnológico.

La capacidad expresiva y comunicativa de las imágenes fijas o en movimiento, acompañadas de locuciones de audio, música, etc. son capaces de recrear desde acontecimientos históricos y experiencias reales vividas, hasta relatos de ficción como cuentos populares, leyendas y fábulas, utilizando escenarios y ambientes imaginarios.

En el digital storytelling se plasman las producciones y expresiones artísticas que hacen converger la capacidad de inventiva, la imaginación, el ingenio, la creatividad y la originalidad de los autores. Esta técnica de narración digital, según Robin (2008), permite recrear contenidos audiovisuales con una gran carga expresiva, haciendo uso de sencillas herramientas de edición de montajes que combinan imágenes gráficas, ilustraciones (dibujos, mapas,....), animaciones, música... El despliegue creativo que supone su diseño, le convierte en una interesante estrategia a implementar en los diversos contextos educativos, ya que permite transmitir ideas, información o mensajes de forma directa y sintética, y supone la puesta en práctica de competencias diversas. Con la creación de relatos digitales se promueve la resolución de problemas, se potencia la búsqueda y presentación de respuestas alternativas originales y críticas capaces de convertir un problema en una ocasión óptima para el aprendizaje.

Desde el punto de vista técnico, los relatos digitales se construyen a partir del lenguaje hipermedial, apoyándose en la transición de elementos icónicos dinámicos que dan lugar a historias complejas, que precisan de la elaboración cuidadosa de un guión literario y técnico que integre la opcionalidad y alternativas que permite el hipertexto. Es evidente que las narrativas digitales promueven nuevas formas de escritura y de interpretación de los mensajes audiovisuales, lo cual exige una formación específica -para algunos, denominada alfabetización digital-, orientada al entrenamiento de las destrezas digitales demandadas en el siglo XXI (Jakes \& Brennan, 2005), que permita a los usuarios decodificar el discurso narrativo en esos nuevos soportes y elaborar el suyo propio, la cual debe ser proporcionada por la escuela.

En este sentido, en el contexto educativo se constata que están surgiendo nuevas metodologías docentes basadas en la construcción de historias hipertextuales (Ohler, 2008). Además, los alumnos, a través de la creación de narrativas digitales, ponen en juego toda una serie de competencias capaces de situar y anclar el aprendizaje, favoreciendo su participación e incremento de su interés y motivación (Miller, 2008). Por ello, en numerosas escuelas se está apostando por actividades centradas en la construcción de relatos desde esta perspectiva, dadas sus características y potencialidades educativas, obteniéndose interesantes resultados (Bull, Kajder \& Albaugh, 2005) (Dreon, Kerper \& Landis, 2011) (Rodríguez y Londoño, 2010). 
La necesidad de orientar la formación del profesorado hacia propuestas innovadoras, que impliquen el uso de las herramientas digitales, ha hecho que en la asignatura de Tecnologías de la Información y Comunicación aplicadas a la Educación (TICAE) del Grado de Maestro de la Universidad de Oviedo se haya propuesto la creación de digital storytelling con una finalidad formativa y como recurso didáctico.

\section{Digital Storytelling en la formación de los futuros maestros}

\section{Contexto}

En la asignatura Tecnologías de la Información y Comunicación aplicadas a la Educación Primaria (TICAEP) del grado de Maestro de Educación Primaria de la Facultad de Formación del Profesorado y Educación de la Universidad de Oviedo (España), dotada de 6 créditos ECTS, se contempla la introducción de las nuevas tecnologías y las herramientas de la Web 2.0 no sólo como objeto de estudio, sino también como medio para evaluar los aprendizajes de los estudiantes y para constatar el nivel de adquisición de las competencias específicas, orientadas a que sean capaces de:

- Reflexionar sobre el impacto de las TIC en la sociedad y la educación.

- Dominar el lenguaje audiovisual y de los medios de comunicación para favorecer su análisis crítico y su aplicación didáctica.

- Conocer y utilizar programas informáticos y aplicaciones multimedia con fines educativos para su posterior explotación didáctica.

- Manejar instrumentos apropiados para facilitar el acceso, selección y gestión de la información multiformato de carácter educativo de Internet.

- Diseñar y evaluar aplicaciones multimedia y recursos digitales educativos.

- Aplicar las herramientas de la Web 2.0 (blogs, wikis, etc.) para potenciar el aprendizaje colaborativo en los contextos educativos.

La mencionada asignatura posee un carácter teórico y práctico. Los contenidos teóricos contribuyen a identificar el marco conceptual y epistemológico al que se adscriben las TIC, presentando las diversas corrientes pedagógicas existentes relativas al diseño, desarrollo y organización de las TIC en la educación. Por su parte, el componente práctico de la asignatura se orienta al desarrollo de habilidades de carácter instrumental para el análisis, el diseño y la evaluación de medios audiovisuales e informáticos, y para el manejo de herramientas tecnológicas asociadas a la Web 2.0 para fomentar la comunicación, la interacción y la realización de proyectos colaborativos en el contexto educativo (Del Moral y Villalustre, 2010). 
Las prácticas de laboratorio se conciben como escenarios en donde los estudiantes adquieren y consolidan las competencias específicas e instrumentales que los cualifiquen como futuros maestros de la escuela 2.0, en la que desarrollarán su actividad docente. $\mathrm{Y}$ es en ese marco en el que se plantea a los estudiantes la realización de digital storytelling de forma colaborativa, como medio para alcanzar los objetivos propuestos en la asignatura y para dotarles de las competencias tecnológicas necesarias.

\section{Objetivos formativos para la creación de digital storytelling}

Durante el curso 2010/11, una de las prácticas que se propuso a los futuros maestros fue la realización -de forma colaborativa- de una narración digital o digital storytelling, a modo de cuento, que tuviera una intencionalidad educativa y permitiera su explotación didáctica en el aula de primaria, para transmitir valores como la solidaridad, el respeto al medio ambiente, la amistad, la tolerancia frente a la diversidad, etc. Para lo cual debían adoptar la técnica de animación stop motion para generar un relato a partir de la sucesión de imágenes fijas que den la sensación de movimiento. Con la mencionada propuesta se pretendía que los futuros maestros aprendieran a:

- Construir relatos a partir de recursos digitales multiformato.

- Desarrollar estrategias y técnicas narrativas creativas para contar historias.

- Manejar herramientas tecnológicas (Microsoft Photo Story o MovieMaker)

- Dominar el lenguaje audiovisual y la lógica hipertextual.

- Trabajar colaborativamente.

- Descubrir el potencial didáctico de los digital storytelling.

\section{Pautas metodológicas para su ejecución}

Los estudiantes tenían que diseñar una narración digital a modo de cuento, utilizando la técnica de animación stop motion. Organizados en grupos de 4 personas, debían tomar decisiones de manera consensuada y colaborativamente, poniendo en juego sus habilidades comunicativas para integrar las aportaciones de todos los miembros del grupo y lograr un resultado óptimo. Para ello debían:

1) Elaborar y escribir un guión literario inicial en el que, a través del formato cuento, se potenciaran valores como la amistad, la solidaridad, la responsabilidad, la honestidad, etc.

Como esquema de trabajo previo, debían crear un Diagrama Visual del Retrato de la Historia (Dillingham, 2001) para delimitar: 1) El comienzo, es decir, los fundamentos de la historia a narrar; 2) El problema, el momento de tensión; 3) El Conflicto, momento álgido de la historia; 4) La Solución, el 
desenlace al conflicto presentado; y por último, 5) El final, donde se establecía la conclusión, la moraleja, etc.

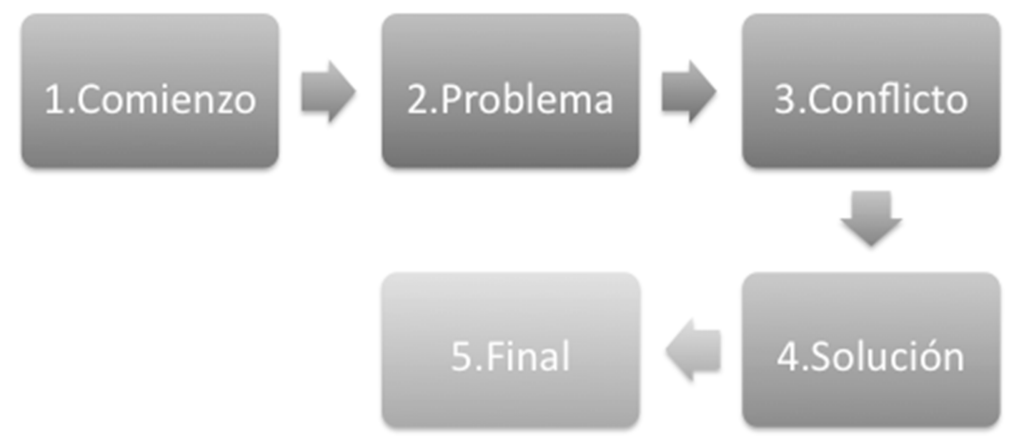

Gráfico 1. Diagrama Visual del Retrato de la Historia (adaptado de Dillingham, 2001)

2) Diseñar un storyboard para determinar, de forma secuencial, el conjunto de elementos multimedia que acompañará al guión literario anteriormente elaborado.

3) Utilizar un programa informático (Microsoft Photo Story o MovieMaker, ambos gratuitos) para efectuar el montaje de los guiones elaborados en el soporte digital.

4) Crear una narración digital, -de aproximadamente 3 minutos-, mediante la técnica del stop motion, a partir del montaje de las fotografías realizadas por ellos mismos. Generalmente fueron utilizadas alrededor de 250 fotografías, las cuales a modo de fotogramas debían superponerse para que su visionado continuo generara la sensación de movimiento.

Los discentes podían utilizar diferentes recursos visuales para elaborar sus composiciones. Algunos se decantaron por la utilización de muñecos de plastilina, elaborados por ellos mismos, convirtiéndolos en los protagonistas de sus narraciones. Otros, por dibujos de papel articulados. Varios decidieron recuperar los juguetes de la infancia para realizar sus creaciones (Playmobil, Barbis, etc.). Y otros, optaron por combinar varios elementos como, por ejemplo, secuencias de imágenes reales junto con otras de imágenes animadas. 


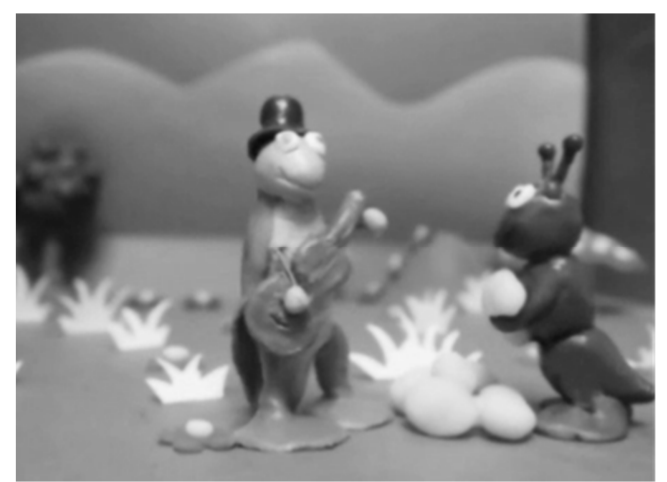

Imagen 1. Narración digital realizada con muñecos de plastilina, elaborada por estudiantes del Grado de Maestro de Educación Primaria.

http://www.youtube.com/watch?edit=vd\&v=D77LMTnHkWU

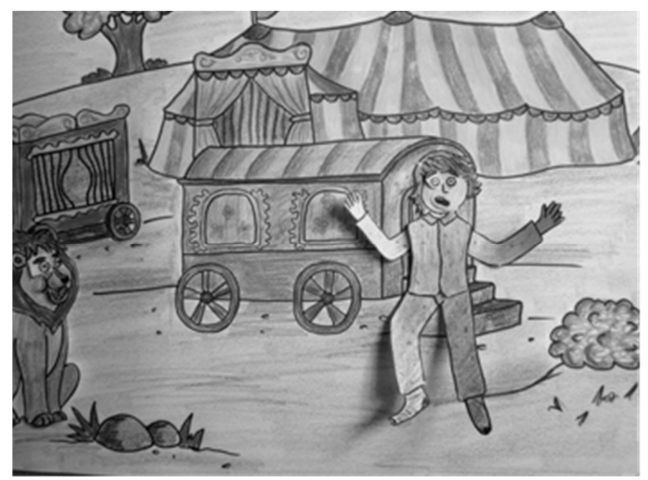

Imagen 2. Narración digital realizada con dibujos de papel articulados, elaborada por estudiantes del Grado de Maestro de Educación Primaria.

En cualquier caso, debían crear no solo el escenario en el cual se desarrollaba la historia sino también los protagonistas que contribuían a darle vida. Controlando, de este modo, todos los aspectos artísticos y narrativos del relato digital.

5) Una vez concretados los aspectos visuales de la narración, tenían que añadir los elementos sonoros (locuciones, efectos especiales, onomatopeyas y banda sonora) más acordes con la historia. Los cuales podían editarse previamente con el software gratuito Audacity, e integrar tantos como fueran necesarios en el montaje previo.

Tras concluir la narración digital, debían elaborar una guía didáctica de la misma para orientar su utilización dentro del aula de primaria, concretamente, explicitando: 
a) Los objetivos perseguidos con la narración digital creada

b) Los valores que se potencian con ella

c) Una breve explicación de cómo se utilizaría dentro del aula Educación Primaria

d) Las competencias que se pueden desarrollar con la misma

e) Nivel educativo, asignatura y conocimientos previos requeridos para la realización de las actividades formativa apoyadas en la narración digital elaborada.

Hay que señalar que la realización de la práctica de diseño del digital storytelling y la elaboración de su guía didáctica, de forma colaborativa, fue considerada una experiencia muy enriquecedora por parte de los futuros maestros. Además, les permitió desarrollar una serie de competencias y habilidades que trascienden a las específicas de la asignatura vinculadas al manejo de herramientas tecnológicas y al diseño de recursos para su aplicación didáctica -como se ha mencionado-, puesto que se han puesto en juego otras de carácter genérico o transversal, tal y como se refleja a continuación.

\section{Competencias y habilidades desarrolladas}

La práctica propuesta de diseño de digital storytelling permitió que los futuros maestros ejercitaran distintas habilidades y adquirieran competencias muy diversas ligadas a la implementación curricular de las TIC y, simultáneamente, descubrieran las posibilidades didácticas de estos relatos en las aulas de educación primaria, algo de gran utilidad para su futuro desempeño profesional. Entre las competencias desarrolladas cabe mencionarse las siguientes:

Competencias Profesionales (CP):

CP1: Capacidad para dominar las técnicas y propiedades de la expresión audiovisual y la lógica hipertextual.

CP2: Habilidad para concebir, planificar, organizar y gestionar una producción mediática.

CP3: Capacidad para realizar proyectos artísticos con una finalidad educativa y formativa.

CP4: Habilidad para elaborar composiciones escritas y orales en contextos digitales.

CP5: Habilidad para aplicar las TIC en la creación de historias con una finalidad didáctica. 
Competencias Genéricas o Transversales (CG):

CG1: Capacidad para generar y gestionar información multiformato.

CG2: Capacidad para plantear ideas innovadoras y creativas.

CG3: Habilidad para ejercitar el pensamiento crítico y resolver problemas.

CG4: Habilidad para tomar decisiones.

CG5: Capacidad para trabajar en equipo.

CG6: Habilidad para incrementar la sensibilidad estética.

La identificación a priori de las competencias que los estudiantes debían alcanzar con la realización de la práctica descrita permitió guiar todo el proceso creativo y, del mismo modo, facilitar su evaluación.

\section{Criterios y pautas de evaluación}

Se adoptó una evaluación continua y formativa, que ayudó a constatar el progreso cognitivo de los estudiantes, medido a partir de las competencias adquiridas y/o desarrolladas con la realización de los digital storytelling, tanto durante las distintas fases del proceso del diseño, como al final, valorando la calidad del relato digital en su conjunto.

Este proceso evaluativo en base a las competencias, -anteriormente enunciadas-, se articuló en función de cuatro dimensiones que posibilitaron el seguimiento puntual de los logros de los discentes, y permitió determinar en qué medida éstos habían adquirido las competencias delimitadas con la creación de las narrativas digitales. 


\begin{tabular}{|c|c|c|c|}
\hline Dimensión & Tareas & Competencias & \begin{tabular}{|c|}
$\begin{array}{c}\text { Criterios de } \\
\text { evaluación }\end{array}$ \\
\end{tabular} \\
\hline \multirow{3}{*}{ Digital } & $\begin{array}{l}\text { Utilización de la } \\
\text { herramienta tecnológica } \\
\text { (Photo Story o } \\
\text { MoviMaker) }\end{array}$ & $\begin{array}{l}\text { CP3; CP5. } \\
\text { CG1; CG4; CG5. }\end{array}$ & $\begin{array}{l}\text { Adecuada utilización y } \\
\text { explotación de los } \\
\text { recursos que ofrece la } \\
\text { herramienta } \\
\text { tecnológica } \\
\text { seleccionada. }\end{array}$ \\
\hline & $\begin{array}{l}\text { Elaboración del story- } \\
\text { board. }\end{array}$ & $\begin{array}{l}\text { CP1; CP2; CP3; } \\
\text { CP4. } \\
\text { CG2; CG4; CG5 }\end{array}$ & $\begin{array}{l}\text { Coherencia en la } \\
\text { planificación del } \\
\text { story-board. }\end{array}$ \\
\hline & $\begin{array}{l}\text { Empleo de la técnica } \\
\text { stop-motion }\end{array}$ & $\begin{array}{l}\text { CP1; CP3; CP5. } \\
\text { CG1; CG2; CG3; } \\
\text { CG5; CG6. }\end{array}$ & $\begin{array}{l}\text { Correcto montaje de } \\
\text { las imágenes según la } \\
\text { técnica del stop- } \\
\text { motion. }\end{array}$ \\
\hline \multirow[b]{2}{*}{ Narrativa } & $\begin{array}{l}\text { Selección y } \\
\text { planificación de la } \\
\text { temática }\end{array}$ & $\begin{array}{l}\text { CP1; CP4. } \\
\text { CG2; CG4; CG5. }\end{array}$ & $\begin{array}{l}\text { Idoneidad de la } \\
\text { temática a la finalidad } \\
\text { planteada con los } \\
\text { digital storytelling }\end{array}$ \\
\hline & $\begin{array}{l}\text { Elaboración de la } \\
\text { historia a través del } \\
\text { Diagrama Visual del } \\
\text { Retrato de la Historia }\end{array}$ & $\begin{array}{l}\text { CP1; CP2; CP4. } \\
\text { CG2; CG4; CG5. }\end{array}$ & $\begin{array}{l}\text { Coherencia en la } \\
\text { estructura narrativa: } \\
\text { comienzo, problema, } \\
\text { conflicto, solución, } \\
\text { final. }\end{array}$ \\
\hline \multirow[t]{2}{*}{ Creativa } & $\begin{array}{l}\text { Creación de los recursos } \\
\text { multiformato }\end{array}$ & $\begin{array}{l}\text { CP2; CP3; CP5. } \\
\text { CG1; CG2; CG4; } \\
\text { CG5; CG6. }\end{array}$ & $\begin{array}{l}\text { Originalidad en la } \\
\text { selección de recursos } \\
\text { y en su utilización } \\
\text { (plastilina, playmobil, } \\
\text { barbis, etc.) }\end{array}$ \\
\hline & $\begin{array}{l}\text { Determinación de la } \\
\text { apariencia audiovisual } \\
\text { final del relato digital }\end{array}$ & $\begin{array}{l}\text { CP2; CP3; CP5. } \\
\text { CG1; CG2; CG3; } \\
\text { CG5; CG6. }\end{array}$ & $\begin{array}{l}\text { Capacidad creativa } \\
\text { para el correcto } \\
\text { montaje de la historia }\end{array}$ \\
\hline \multirow[t]{2}{*}{ Didáctica } & $\begin{array}{l}\text { Formulación de una } \\
\text { historia capaz de } \\
\text { desarrollar } \\
\text { competencias }\end{array}$ & $\begin{array}{l}\text { CP3; CP4; CP5. } \\
\text { CG2; CG4; CG5. }\end{array}$ & $\begin{array}{l}\text { Potencialidad } \\
\text { didáctica del relato } \\
\text { para desarrollar } \\
\text { competencias: } \\
\text { lingüística, social y } \\
\text { ciudadana, etc. }\end{array}$ \\
\hline & $\begin{array}{l}\text { Creación de un relato } \\
\text { con capacidad para } \\
\text { transmitir valores }\end{array}$ & $\begin{array}{l}\text { CP3; CP4; CP5. } \\
\text { CG2; CG4; CG5; } \\
\text { CG6. }\end{array}$ & $\begin{array}{l}\text { Capacidad para } \\
\text { transmitir valores } \\
\text { positivos en educación } \\
\text { primaria }\end{array}$ \\
\hline
\end{tabular}

Tabla 1. Criterios de evaluación de los aprendizajes en función de cuatro dimensiones 
En la tabla 1 se exponen los criterios de evaluación de las competencias adquiridas y/o desarrolladas por los estudiantes con la realización de los digital storytelling, con una doble intencionalidad, por un lado, identificar la incidencia real y la potencialidad de la actividad propuesta, por su carácter integrador de múltiples aspectos, en la capacitación docente; $\mathrm{y}$, por otro, explicitar o dar a conocer a los estudiantes -a modo de rúbrica- las pautas específicas de evaluación de las narraciones digitales que elaboren, para que les sirva de referencia y puedan adaptar, modificar y reelaborar sus producciones en función de las mismas con el fin de obtener unos resultados óptimos.

\section{Evaluación de las Competencias adquiridas por los estudiantes con los Digital Storytelling}

Tras la creación de las historias digitales siguiendo las pautas aquí delimitadas, se determinó el nivel de competencias adquirido por los estudiantes a través de las narrativas elaboradas. Los resultados obtenidos se muestran a continuación.

\section{El universo muestral}

La muestra de estudio estuvo formada por 167 estudiantes universitarios procedentes de la asignatura de Tecnologías de la Información y Comunicación aplicadas a la Educación (TICAE) del Grado de Maestro de Educación Primaria de la Universidad de Oviedo, de los cuales un $74 \%$ eran mujeres y un $26 \%$ hombres.

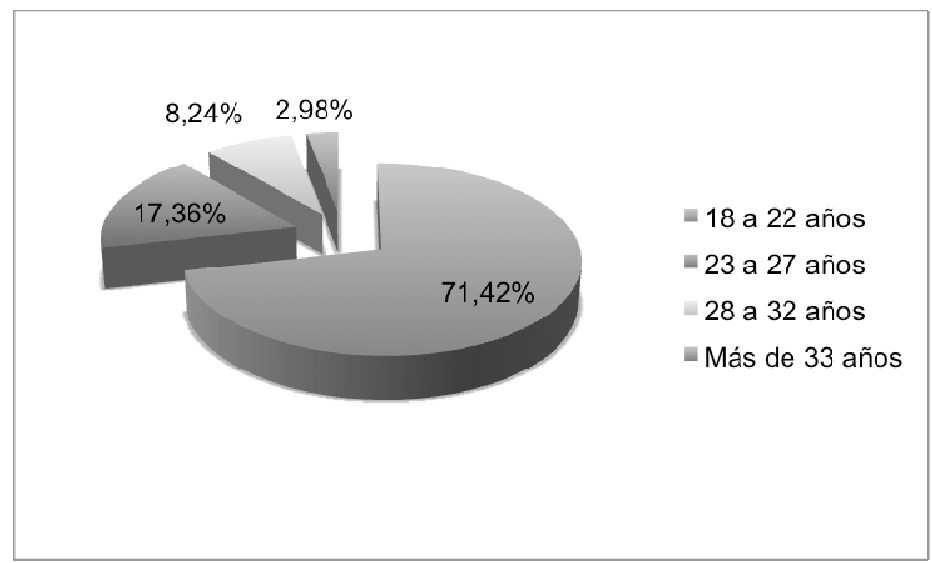

Gráfico 2. Distribución porcentual de los estudiantes en función de su rango de edad

El rango de edades se encuentra entre los 18 y 33 años, distribuidos del siguiente modo: un $71,42 \%$ de 18 a 22 años, un $17,36 \%$ de 23 a 27 años, un $8,24 \%$ de 28 a 32 años y, un $2,98 \%$ más de 33 años, tal y como se refleja en el gráfico 2 . 


\section{Procedimiento e instrumento de evaluación}

Para valorar las competencias adquiridas por los futuros maestros a través del diseño de los digital storytelling se creó una rúbrica de evaluación de carácter analítica (tabla 3), con la que se pretendía evaluar sus producciones finales, determinar su nivel competencial y obtener una visión de conjunto de los logros alcanzados con la práctica. Dicha rúbrica se mostró a los estudiantes universitarios al inicio de la actividad práctica con el fin de clarificar y detallar lo que se esperaba de ellos, en función de las competencias específicas implicadas en el diseño del proyecto (tabla 2).

\begin{tabular}{|l|l|}
\hline \multicolumn{1}{|c|}{ COMPETENCIAS } & \multicolumn{1}{|c|}{ COMPETENCIAS ESPECÍFICAS } \\
\hline Digitales & $\begin{array}{l}\text { 1. Capacidad para dominar las técnicas (stop-motion) y propiedades de } \\
\text { la expresión audiovisual (utilización de planos, movimientos de cámara, } \\
\text { etc.) } \\
\text { 2. Capacidad para generar y gestionar información multiformato (banda } \\
\text { sonora, locuciones, efectos especiales, imágenes, etc.). } \\
\text { 3. Habilidad para la utilización adecuada de programas informáticos } \\
\text { (Movimaker, PhotoStory, Audacity, etc.) }\end{array}$ \\
\hline Narrativas & $\begin{array}{l}\text { 4. Habilidad para elaborar composiciones escritas y orales en contextos } \\
\text { digitales. } \\
\text { 5. Capacidad para seleccionar y planificar una historia siguiendo un } \\
\text { esquema previamente preestablecido (Diagrama visual del retrato de la } \\
\text { historia) } \\
\text { 6. Habilidades lingüísticas y gramaticales para la elaboración de los } \\
\text { diálogos y la secuencia narrativa. }\end{array}$ \\
\hline Creativas & $\begin{array}{l}\text { 7. Capacidad para plantear ideas innovadoras y creativas. } \\
\text { 8. Habilidad para ejercitar el pensamiento crítico y resolver problemas } \\
\text { de manera colaborativa. } \\
\text { 9. Habilidad para utilizar y ejercitar la sensibilidad estética en la } \\
\text { producción del relato digital. }\end{array}$ \\
\hline $\begin{array}{l}\text { 10. Capacidad para realizar proyectos artísticos con una finalidad } \\
\text { educativa y didáctica. } \\
\text { 11. Habilidad para transmitir mensajes y/o valores a través del lenguaje } \\
\text { hipertextual. } \\
\text { 12. Habilidad para utilizar diferentes estrategias didácticas capaces de } \\
\text { potenciar los recursos digitales y expresivos utilizados en el relato. }\end{array}$ \\
\hline Didácticas
\end{tabular}

Tabla 2. Delimitación de competencias especificas dentro de las digitales, narrativas, creativas y didácticas

El ejercicio de visibilización de los criterios de evaluación ayudó a que los estudiantes se ajustaran a los requerimientos de la práctica, sirviendo de feed-back inmediato para adoptar los mecanismos necesarios orientados a perfeccionar sus producciones en cada fase. La rúbrica analítica permitió determinar el nivel competencial que adquirieron, la cual se presenta a continuación: 


\begin{tabular}{|c|c|c|c|}
\hline \multirow{2}{*}{ COMPETENCIAS } & \multicolumn{3}{|c|}{ NIVEL DE COMPETENCIA } \\
\hline & BAJO & MEDIO & ALTO \\
\hline Digitales & $\begin{array}{l}\text { - No se aprovechan } \\
\text { todas las posibilidades } \\
\text { técnicas del programa } \\
\text { informático. } \\
\text { - No gestiona } \\
\text { adecuadamente la } \\
\text { información } \\
\text { multiformato ni se } \\
\text { utiliza correctamente } \\
\text { la técnica del stop- } \\
\text { motion. }\end{array}$ & $\begin{array}{l}\text { - Se realiza una } \\
\text { adecuada utilización } \\
\text { de la herramienta } \\
\text { tecnológica mediante } \\
\text { el empleo de la } \\
\text { técnica del stop- } \\
\text { motion, pero sin gran } \\
\text { fluidez entre cada } \\
\text { imagen. } \\
\text { - La utilización de } \\
\text { planos, movimientos } \\
\text { de cámara, banda } \\
\text { sonora, etc. es escasa. }\end{array}$ & $\begin{array}{l}\text { - Se emplea } \\
\text { adecuadamente el } \\
\text { programa informático } \\
\text { indicado, sacándole el } \\
\text { máximo provecho a } \\
\text { todas sus opciones. } \\
\\
\text { - Se crea un relato } \\
\text { digital mediante la } \\
\text { utilización adecuada } \\
\text { del stop-motion. } \\
\text { Empleando numerosos } \\
\text { recursos audiovisuales } \\
\text { y efectos especiales. }\end{array}$ \\
\hline Narrativas & $\begin{array}{l}\text { - La temática abordada } \\
\text { en el relato digital no } \\
\text { se adecua a los } \\
\text { criterios establecidos. } \\
\text { Y el relato no posee } \\
\text { una correcta secuencia } \\
\text { narrativa. } \\
\text { - El diagrama visual } \\
\text { del retrato de la } \\
\text { historia se presenta de } \\
\text { manera incoherente. }\end{array}$ & $\begin{array}{l}\text { - La selección de la } \\
\text { temática es la } \\
\text { adecuada. No } \\
\text { presenta errores } \\
\text { gramaticales ni } \\
\text { ortográficos. } \\
\text { - La historia narrada } \\
\text { en formado digital es } \\
\text { algo confusa, al igual } \\
\text { que el diagrama } \\
\text { visual del retrato de } \\
\text { la historia. }\end{array}$ & $\begin{array}{l}\text { - El tema abordado } \\
\text { responde claramente a } \\
\text { la finalidad planteada } \\
\text { con una correcta } \\
\text { gramática. } \\
\text { - Su desarrollo es el } \\
\text { adecuado, dejando } \\
\text { patente la coherencia } \\
\text { interna en la estructura } \\
\text { narrativa de la } \\
\text { historia. }\end{array}$ \\
\hline Creativas & $\begin{array}{l}\text { - La puesta en escena } \\
\text { de la historia abordada } \\
\text { es pobre, y el montaje } \\
\text { de los elementos } \\
\text { audiovisuales no se } \\
\text { realiza } \\
\text { adecuadamente. }\end{array}$ & $\begin{array}{l}\text { - Para narrar la } \\
\text { historia se utilizan } \\
\text { diferentes recursos } \\
\text { audiovisuales, } \\
\text { aunque en el montaje } \\
\text { final de todos los } \\
\text { elementos le falta } \\
\text { capacidad expresiva e } \\
\text { imaginativa. } \\
\end{array}$ & $\begin{array}{l}\text { - Se narra la historia } \\
\text { utilizando efectos } \\
\text { especiales, ilusiones } \\
\text { ópticas, etc. para } \\
\text { potenciar la capacidad } \\
\text { expresiva del relato } \\
\text { mediante la } \\
\text { originalidad e } \\
\text { innovación. }\end{array}$ \\
\hline Didácticas & $\begin{array}{l}\text { - El relato digital } \\
\text { creado carece de } \\
\text { potencial didáctico, } \\
\text { capaz de transmitir } \\
\text { valores positivos. }\end{array}$ & $\begin{array}{l}\text { - El digital } \\
\text { storytelling creado es } \\
\text { capaz de potenciar el } \\
\text { desarrollo de } \\
\text { competencias, } \\
\text { aunque utilizando } \\
\text { estrategias didácticas } \\
\text { poco novedosas. }\end{array}$ & $\begin{array}{l}\text { - La historia narrada } \\
\text { posee la capacidad } \\
\text { didáctica para } \\
\text { estimular la } \\
\text { adquisición de valores } \\
\text { mediante la utilización } \\
\text { de interesantes } \\
\text { estrategias. }\end{array}$ \\
\hline
\end{tabular}

Tabla 3. Rúbrica de evaluación holística utilizada para valorar el nivel de competencias adquirido por los estudiantes con la realización de los digital storytelling 
La rúbrica descrita facilitó la evaluación de las producciones finales elaboradas por los estudiantes, y ayudó a determinar el nivel de competencias y habilidades adquiridas, estableciendo diferentes niveles de rendimiento, tal como se presenta a continuación.

\section{Resultados obtenidos}

A partir de la rúbrica y de los criterios de evaluación establecidos en las tablas 1,2 y 3 se determinó el nivel competencial (alto, medio y bajo) adquirido por los estudiantes universitarios con la actividad propuesta. Así, el 53,7\% de los discentes adquirió a través de la realización de los digital storytelling un alto nivel de competencias. Ello implica, que supieron utilizar adecuadamente las herramientas informáticas empleadas para ello (Microsoft Photo Story o MovieMaker, Audacity, etc.) y que crearon un relato digital, a partir de la esmerada técnica del stop-motion, capaz de transmitir valores, tales como el respeto, la tolerancia, la honestidad, etc. mediante la utilización de interesantes estrategias didácticas.

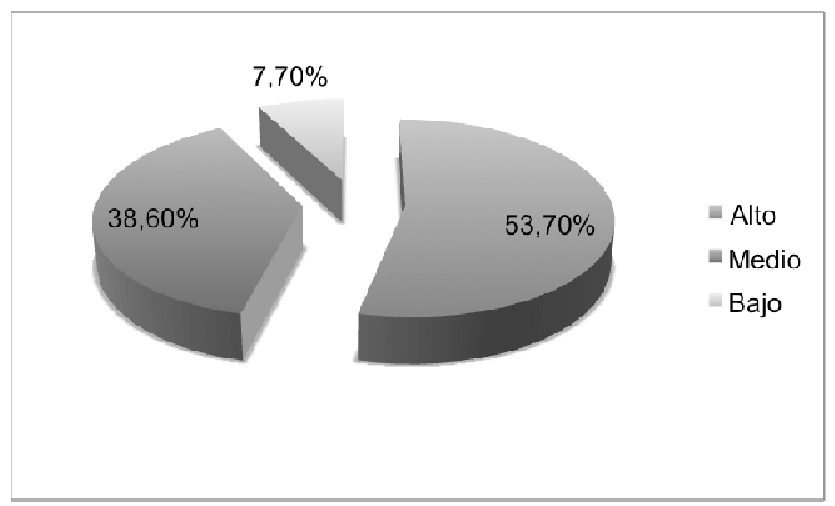

Gráfico 3. Distribución porcentual de los diferentes niveles de competencias adquiridos por los estudiantes universitarios

Igualmente, demostraron haber puesto en práctica toda su capacidad creativa para generar un relato original, imaginativo e innovador, capaz de expresar claramente, a través de diferentes elementos audiovisuales (música, sonidos, locuciones, imágenes, etc.) y efectos especiales (ópticos, digitales, etc.), para crear historias impregnadas de gran dosis de invención y talento.

Por otro lado, un $38,6 \%$ de los discentes mostró poseer un nivel de competencias medio, lo cual implica que adquirieron diversas competencias y habilidades, encaminadas a favorecer la realización de composiciones escritas en contextos digitales, y con una intencionalidad educativa. Sin embargo, otras no se crearon como cabía esperar, al carecer de capacidad expresiva y artística, pues claramente necesitaban de una mayor dedicación para su correcta ejecución. 
Por último, tan sólo el 7,7\% de los estudiantes mostró un nivel de competencias bajo, lo que significa que si bien desarrollaron algunas de las competencias delimitadas con la actividad planteada, lo hicieron en menor medida, e incluso, algunas de ellas no las adquirieron. En estos casos, los estudiantes desaprovecharon la capacidad didáctica del digital storytelling para transmitir valores educativos, al no adecuarse a las temáticas establecidas, ni realizar un montaje audiovisual original y creativo. Este porcentaje reducido de estudiantes, que obtuvieron un nivel de competencias bajo, se corresponde con aquellos que no acudieron regularmente a las sesiones prácticas de la asignatura, lo que se reflejó en sus producciones finales, puesto que no se beneficiaron del asesoramiento continuo dispensado en el desarrollo en las mismas, orientado a reconducir y mejorar los relatos digitales realizados.

Un análisis más específico en función de las diferentes competencias puestas en juego, revela que algo más del $67 \%$ de los discentes adquirió un alto nivel de competencias creativas y, el $29,10 \%$ un nivel medio. Ello pone de manifiesto, el gran interés e implicación mostrado por los futuros maestros para diseñar unas producciones digitales originales e innovadoras. De igual modo, alrededor del $57 \%$ de los estudiantes universitarios mostró lograr un alto nivel de competencias digitales, lo cual implica que han adquirido las capacidades y habilidades necesarias para utilizar adecuadamente diversos programas informáticos (Movimaker, Microsoft PhotoStory, Audacity, etc.), han gestionado correctamente información multiformato $\mathrm{y}$ han dominado diferentes elementos propios del lenguaje audiovisual (tipo de planos, movimientos de cámara, etc.), todo ello, mediante la realización de los relatos digitales.

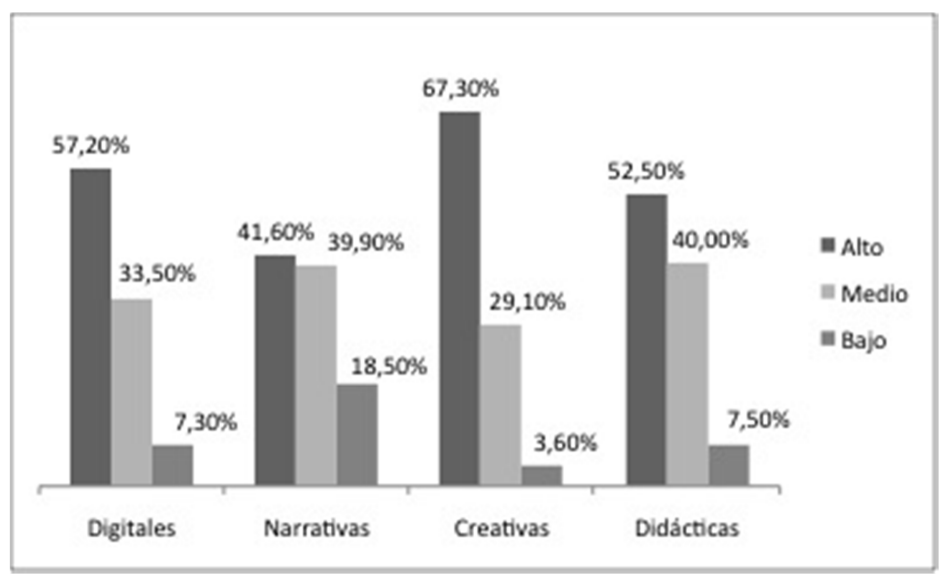

Gráfico 4. Distribución porcentual de los niveles específicos de competencias adquiridos por los futuros maestros

Por otro lado, según se aprecia en el gráfico 4, casi la mitad (41,60\%) de los futuros maestros demostraron adquirir y/o desarrollar un alto nivel de competencias narrativas, $\mathrm{y}$ en valores similares $(39,90 \%)$ se encuentran aquellos con un nivel medio. Mientras 
que casi el 19\% de los mismos, se sitúa en un nivel bajo de competencias narrativas, lo cual implica que no han puesto en juego todas las competencias necesarias para elaborar las composiciones digitales, con una estructura y gramática aceptable, capaz de potenciar la capacidad expresiva y narrativa del relato digital elaborado.

Por último, el nivel de competencias didácticas se sitúa en rangos muy similares a los generales. Así, más del 52\% de los estudiantes adquirieron un nivel alto, y un $40 \%$ un nivel medio. Con ello, los futuros maestros ejercitaron habilidades para transmitir mensajes y/o valores a través del lenguaje hipertextual, con una finalidad educativa y didáctica, objetivo principal de la actividad a desarrollar.

\section{Conclusiones}

La experiencia innovadora de introducir el diseño de digital storytelling en la formación inicial del profesorado de educación primaria puede considerarse como una interesante y motivadora estrategia didáctica para desarrollar de forma conjunta habilidades digitales y creativas. Al tiempo que se ha revelado como una práctica de trabajo colaborativo de gran potencia para dotar de competencias muy diversas a los estudiantes. Desde el manejo de herramientas informáticas, la elaboración de relatos apoyados en recursos digitales, el diseño de escenarios y personajes, la compleja creación de guiones para dar vida a historietas con una finalidad educativa, hasta la realización del montaje final secuenciado de imágenes, etc. han servido para potenciar las competencias lingüísticas y narrativas a partir de la lectura y escritura de relatos apoyados en imágenes.

Las producciones audiovisuales resultantes pusieron de manifiesto su alto nivel de capacidad creativa para articular diferentes recursos y artificios narrativos junto a componentes más artísticos, apoyados en la imagen y otros elementos icónicos, recurriendo a analogías, símiles, metáforas visuales, hipérboles, asociación de ideas, etc., dotándolas de un gran valor al servicio de la educación.

Se pudo constatar la diversidad de competencias de orden superior que tuvieron ocasión de desarrollar los estudiantes universitarios, puesto que más de la mitad de ellos mostró poseer un alto de nivel de competencias y, algo más del 38\%, un nivel medio. De igual modo, más del $67 \%$ de los futuros maestros obtuvo un alto nivel de competencias creativas, al igual que más de la mitad de ellos, en relación a las competencias digitales y didácticas. Ello, pone de manifiesto su capacidad para concebir, planificar y desarrollar una producción mediática con una finalidad educativa, mediante la utilización de diversos elementos artísticos y narrativos.

Por otro lado, la práctica de creación de digital storytelling fue bien acogida entre los estudiantes participantes. De sus comentarios, -efectuados a lo largo de su ejecución-, se desprenden una serie de efectos positivos inherentes a su desarrollo. Entre ellos, se encuentra el incremento de la motivación e implicación. Los discentes manifestaron desde el inicio su entusiasmo por la producción de los relatos digitales. 
De igual modo, declararon haber puesto en práctica habilidades creativas para elaborar una historia capaz de transmitir valores y desarrollar competencias de diversa índole.

El uso de herramientas digitales supuso un revulsivo para los estudiantes, puesto que ofrecían novedosas oportunidades para la creación y expresión artística que hasta el momento desconocían. En definitiva, y a pesar del gran esfuerzo y dedicación que implicó su realización, valoraron muy positivamente su propuesta y posterior realización como medio para favorecer la adquisición y consolidación de competencias asociadas a la propia asignatura.

\section{Referencias bibliográficas}

BULL, G., KAJDER, S., \& ALBAUGH, S. (2005). Constructing Digital Stories. Learning \& Leading with Technology, 32 (5), 40-42.

DEL MORAL, M. E. Y VILLALUSTRE, L. (2010). Formación del profesor 2.0: desarrollo de competencias tecnológicas para la escuela 2.0. Revista Magister, 23, 59-70.

DREON, O., KERPER, R., \& LANDIS, J. (2011). Digital Storytelling: A Tool for Teaching and Learning in the YouTube Generation. Middle School Journal, 42 (5), 4-9.

DILLINGHAM, B. (2001). Visual portrait of a story: Teaching storytelling. Juneau, AK: School Handout.

HULL, G. \& KATZ, M.L. (2006). Crafting an agentive self. Case studies of digital storytelling. Research in the Teaching of English, 41 (1), 43-81.

JAKES, D.S. \& BRENNAN, J. (2005). Digital Storytelling, Visual Literacy and 21st Century Skills. Tech \& Learning. Tech Forum, New York 2005. http://www.techlearning.com/techlearning/pdf/events/techforum/ny05/Vault_article jakesbrennan.pdf 14/12/2012

LAMBERT, J. (2007). The Digital Storytelling Cookbook. Berkeley, CA: Center for Digital Storytelling.

LUNDBY, K. (ed.) (2008). Digital Storytelling, Mediatized Stories. Selfrepresentations in New Media. Nueva York: Peter Lang Publishing.

MEADOWS, D. (2003). Digital storytelling: research-based practice in new media. Visual Communication. Reflections on practice, 2(2), 189-193.

MILlER, C. H. (2008). Digital Storytelling: A Creator's Guide to Interactive Entertainment. Burlington: Focal Press.

OHLER, J. (2008). Digital Storytelling in the classroom: new media pathways to literacy, learning, and creativity. Thousand Oaks: Corwin Press.

ROBIN, B. (2008). Digital storytelling: a powerful technology tool for the 21 st century classroon. Theory into practice, 47 (3), 220-228. 
RODRÍGUEZ, J. L. Y LONDOÑO, G. (2010). Los relatos digitales como textos multimodales. En Fundación Germán Sánchez Ruipérez. El ebook y otras pantallas, nuevas formas, posibilidades y espacios para la lectura. 18 Jornadas de Bibliotecas Infantiles, Juveniles y Escolares. 27, 28 y 29 mayo 2010. http://www.cilij.fundaciongsr.com/uploads/contenidos/doc/275-1-

Actas $\% 2018 \% 20$ Jornadas $\% 20 \mathrm{de} \% 20$ bibliotecas $\% 20 \% 28$ FGSR $\% 29$.pdf $\#$ page $=73$, $14 / 12 / 2012$

\section{Correspondencia con las autoras:}

Dra. Lourdes VILLALUSTRE MARTÍNEZ

Dra. Ma Esther del MORAL PÉREZ

Profesoras de TIC aplicadas a la Educación en la Universidad de Oviedo.

Facultad de Formación del Profesorado y Educación

$\mathrm{C} /$ Aniceto Sela s/n

33005 Oviedo (Asturias)

e-mail: villalustrelourdes@uniovi.es 